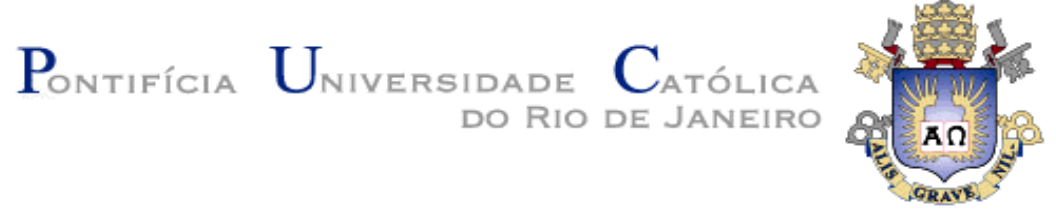

Silvia Neves Salazar

\title{
TRABALHO E EDUCAÇÃO NAS PRÁTICAS DE ECONOMIA SOLIDÁRIA: uma sociabilidade na perspectiva emancipatória?
}

\section{Tese de Doutorado}

Tese apresentada ao Programa de Pós-graduação em Serviço Social do Departamento de Serviço Social da PUC-Rio como requisito parcial para obtenção do título de Doutor em Serviço Social.

Orientadora: Myrtes de Aguiar Macedo 


\section{Pontifícia Universidade C $_{\text {atólica }}$

Silvia Neves Salazar

\section{TRABALHO E EDUCAČ̃O NAS PRÁTICAS DE ECONOMIA SOLIDÁRIA: uma sociabilidade na perspectiva emancipatória?}

Tese apresentada como requisito parcial para obtenção do grau de Doutor pelo Programa de Pósgraduação em Serviço Social do Departamento de Serviço Social do Centro de Ciências Sociais da PUCRio. Aprovada pela Comissão Examinadora abaixo assinada.

Profa. Myrtes de Aguiar Macedo

Orientadora

Departamento de Serviço Social - PUC-Rio

Profa. Lia Tiriba

Departamento de Educação - UFF

Profa. Mônica Maria de Alencar Departamento de Serviço Social - UERJ

Profa. Ana Maria Quiroga Departamento de Serviço Social - PUC-Rio

Prof. Ricardo Emmanuel Ismael de Carvalho Departamento de Sociologia e Política - PUC-Rio

Prof. Nizar Messari

Vice-Decano de Pós-Graduação do Centro de Ciências Sociais - PUC-Rio

Rio de Janeiro, 14 de março de 2008 
Todos os direitos reservados. É proibida a reprodução total ou parcial do trabalho sem autorização da universidade, da autora e do orientador.

\section{Silvia Neves Salazar}

Graduou-se em Serviço Social pela UERJ (Universidade Estadual do Rio de Janeiro) em 1993. É especialista em Políticas Públicas Sociais pela UERJ (Universidade Estadual do Rio de Janeiro) em 1996. Cursou Mestrado em Serviço Social na PUC (Pontifícia Universidade Católica do Rio de Janeiro) em 1998. Participou, como coordenadora, do Projeto de pesquisa "Mapeamento dos empreendimentos econômicos solidários do Estado do Espírito Santo", do Ministério do Trabalho e Emprego em 2005. Tem experiência na área do Serviço Social, com ênfase em estudos sobre o trabalho.

Ficha Catalográfica

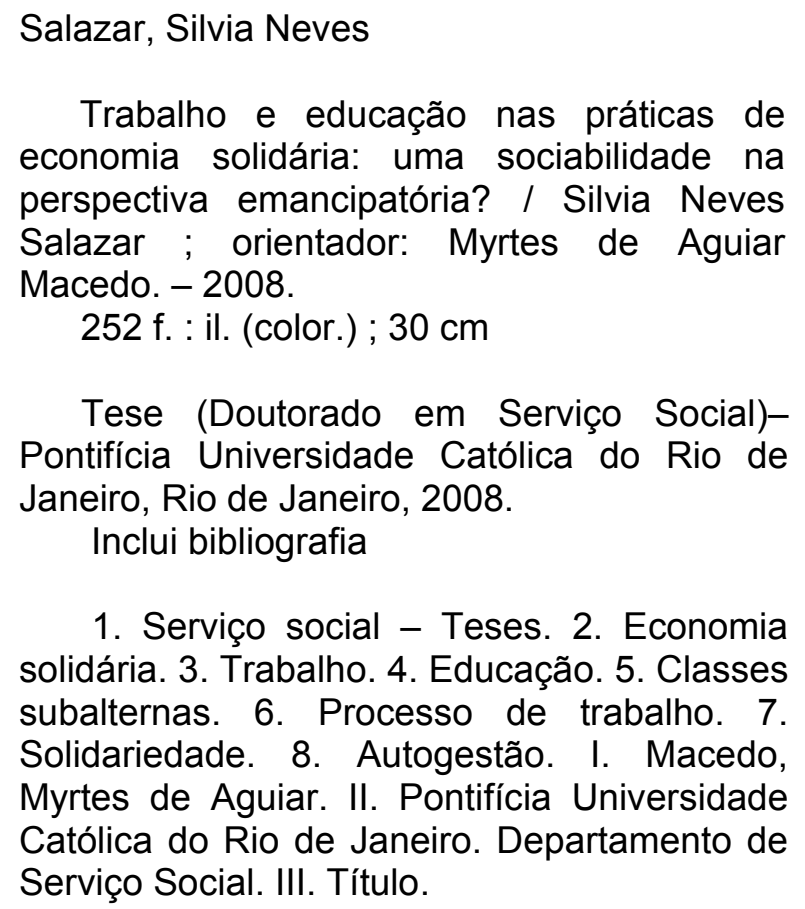

1. Serviço social - Teses. 2. Economia solidária. 3. Trabalho. 4. Educação. 5. Classes subalternas. 6. Processo de trabalho. 7. Solidariedade. 8. Autogestão. I. Macedo, Myrtes de Aguiar. II. Pontifícia Universidade Católica do Rio de Janeiro. Departamento de Serviço Social. III. Título. 
A minha orientadora $\operatorname{Prof}^{\mathrm{a}} \operatorname{Dr}^{\mathrm{a}}$ Myrtes de Aguiar Macedo, pela sua orientação, dedicação e sabedoria na realização deste trabalho.

Ao Welty e Larissa pelo incentivo e alegrias em família.

Aos meus pais Lúcia e Milton pelas orações e torcida. 


\section{Agradecimentos}

Ao meu marido Welty quem sempre me motivou a iniciar e continuar a trajetória difícil do doutorado. Obrigada pelo amor, carinho e compreensão em tantos momentos.

A minha filha Larissa que nasceu ao final deste processo e que com certeza sentiu minha ausência neste segundo ano de vida. Foi doloroso ficar tanto tempo longe de você!!! Mas com certeza vai valer à pena!!!

Aos meus queridos pais Lúcia e Milton pelo incentivo, mesmo que à distância. E especialmente a minha mãe pelas constantes orações.

As minhas irmãs Fernanda e Valéria pela torcida!! Especialmente a Valéria, pela compreensão e carinho, pois invadi sua casa transformando num verdadeiro escritório!!!

Especialmente agradeço a minha orientadora Myrtes, que com sabedoria, compromisso e muita dedicação nas orientações contribuiu decisivamente para o que tem de melhor nesse estudo.

A Inez, Maristela, Alaísa, Necilda, Luzia, Zenilda e Madalena, amigas que dividi mais de perto esses últimos momentos de angústia. Obrigada pelo incentivo!!!

A todos que participam do Fórum de Economia Popular Solidária do Espírito Santo/FEPS pela oportunidade de conhecer e viver de perto algumas experiências do movimento.

Ao Fábio, Gal e Edison que fazem parte do coordenação do FEPS/ES pelas informações preciosas e carinho que sempre me acolheram. 
A Faculdade Salesiana de Vitória pelo apoio, especialmente na gestão dos Professores João Bosco e Geraldo Magela.

$\mathrm{E}$ a todas as pessoas que direta ou indiretamente contribuíram para esta pesquisa. 


\section{Resumo}

Salazar, Silvia Neves; Macedo, Myrtes de Aguiar. Trabalho e Educação nas práticas de Economia Solidária: uma sociabilidade na perspectiva emancipatória? Rio de Janeiro. 2008. 252p. Tese de Doutorado Departamento de Serviço Social, Pontifícia Universidade Católica do Rio de Janeiro.

Esta pesquisa resulta da análise dos processos de trabalho que se constituem na diversidade das unidades produtivas de Economia Solidária na contemporaneidade Brasileira. Neste sentido, busca desvendar as potencialidades dessas práticas na constituição de uma nova sociabilidade, a partir da ênfase nos aspectos extraeconômicos. Através de entrevistas semi-estruturadas, tomamos como base as experiências vivenciadas pelos sujeitos sociais inseridos em 10 (dez) unidades produtivas de Economia Solidária, situadas no estado do Espírito Santo. Pesquisa bibliográfica, documentação referente ao movimento, participação nos eventos, nas plenárias do Fórum Estadual de Economia Popular Solidária/FEPS, assim como nossa participação na realização da $1^{\text {a }}$ e $2^{\text {a }}$ Fases do Mapeamento em Economia Solidária no Estado do Espírito Santo foram fontes que subsidiaram nossa investigação. Desvendar as potencialidades dos processos educativos nos espaços de Economia Solidária exige um esforço crítico constante, situando essas práticas no contexto da dinâmica das relações sociais capitalistas que, diante das novas modalidades de assalariamento, tendem a ser incorporadas ao capital. Entretanto a análise percebe essas experiências também como um dos espaços que manifestam formas diferenciadas da cultura popular, enquanto um conjunto disperso de práticas e representações. Trata-se, portanto, de uma análise que considera as potencialidades do movimento da Economia Solidária no Brasil, dos anos 1990, inserido numa sociedade de classes, o que o caracteriza como um movimento histórico-social complexo e contraditório.

\section{Palavras-chave}

Economia Solidária; trabalho; educação; classes subalternas; processo de trabalho; solidariedade; autogestão. 


\section{Abstract}

Salazar, Silvia Neves; Macedo, Myrtes de Aguiar. Work and Education on the Solidary Economy pratices: is it sociability on the emancipator perspective? Rio de Janeiro. 2008. 252p. Tese de Doutorado - Departamento de Serviço Social, Pontifícia Universidade Católica do Rio de Janeiro.

This research is a result from analyze of work's processes that are constituted in the diversity among productive units of solidarity economy in Brazilian contemporaneousness. In this purpose the study searches to clear up the potentiality of these practices in the constitution of a new sociability from the emphasis on extraeconomic aspects. Through semi-structured interviews based on experiences from people that are in ten productive units of solidarity economy in the state of Espírito Santo.Bibliographic research, documents about the movement, participation on events, on plenary assemblies of "Forum Estadual de Economia Popular Solidária"/FEPS, and our participation on first and second stages to elaborate the map of solidarity economy in the state of Espírito Santo supported our investigation. The discovery of potentiality of educational processes in solidarity economy demands a constant critical efforts, setting these kind of actions in the context of dynamic of social relations that faced with new kinds of employments with a tendency to incorporate to the capital. However the analyze notices that these experiences work also such as a space that reveals different forms of popular culture, like a set of loose practices and representations. Thus, it is an analyze that concerns the potentialities of the movement of solidarity economy in Brazil, in the 1990s, inserted in a society of classes, it becomes in a complex and contradictory social historic movement.

\section{Keywords}

Solidary Economy; work; education; corner classes; work process; solidarity; self management. 


\section{Sumário}

1. Introdução

2. A Economia Solidária nos anos 1990: principais controvérsias 26 no debate contemporâneo

2.1. A Economia Solidária e seu ressurgimento no Brasil dos anos 1990

2.2. Divergências no debate contemporâneo: principais controvérsias

2.3. Limites e potencialidades na constituição de uma nova 70 sociabilidade - algumas contribuições

2.4. Categorias centrais da Economia Solidária

3. A centralidade do trabalho no contexto das transformações societárias

3.1. O trabalho no contexto da reestruturação produtiva e do projeto neoliberal

3.2. Trabalho abstrato e trabalho concreto em referência as atuais 101 mudanças societárias

3.3. Por que afirmar a centralidade do trabalho na 110 contemporaneidade?

3.4. Redução do trabalho assalariado e crescimento da 114 informalidade no Brasil

4. Economia Solidária como proposta no governo lula: 125 características que assume na contemporaneidade

4.1. Um breve resgate da Política de Emprego nos anos 1990 tendências atuais 
4.2. A criação Secretaria Nacional Economia Solidária no governo Lula

4.3. Principais características Economia Solidária no Brasil anos 2000

4.4. A Economia Solidária no Estado do Espírito Santo

145

150

5. A relação educação/trabalho nas unidades de Economia 166 Solidária

5.1. Situando o campo de pesquisa 167

5.2. A concepção de trabalho: da lógica capitalista e da lógica da 177 Economia Solidária

5.3. A gestão coletiva nas unidades produtivas

5.4. O papel das entidades de apoio na formação dos grupos de 206 Economia Solidária

5.5. O significado do trabalho para os grupos de Economia 216 Solidária

5.6. Processos educativos: particularidade nas práticas de 221 Economia Solidária

6. Considerações finais

7. Referências Bibliográficas

8. Anexos 


\section{Lista de siglas}

Abicred - Associação Brasileira de Instituições de Micro-Crédito ADS - Agência de Desenvolvimento Solidário da CUT AEC - Associação de Educação Católica do Estado do Espírito Santo ANTEAG - Associação Nacional dos Trabalhadores em Empresas de Autogestão e Participação Acionária BID - Banco Interamericano de Desenvolvimento BM - Banco Mundial BIRD - Banco Interamericano para Reconstrução e Desenvolvimento BNDES - Banco Nacional de Desenvolvimento Econômico e Social CAGED - Cadastro Geral de Empregados e Desempregados do TEM CDDH - Centro de Defesa dos Direitos Humanos da Serra CEPAL - Comissão Econômica para a América Latina e o Caribe CGE - Comissão Gestora Estadual CODEFAT - Conselho Deliberativo do Fundo de Amparo ao Trabalhador CONCRAB - Confederação das Cooperativas de Reforma Agrária do Brasil CONTAG - Confederação dos Trabalhadores da Agricultura COPPE - Coordenação dos Programas de Pós-graduação de Engenharia CUT - Central Única dos Trabalhadores

DIEESE - Departamento Intersindical de Estatística e Estudos SócioEconômicos

DRT - Delegacia Regional do Trabalho EGE - Equipe Gestora Estadual

FASE - Federação de Órgãos para Assistência Social e Educacional FAT - Fundo de Amparo ao Trabalhador FBES - Fórum Brasileiro de Economia Solidária FEPS - Fórum de Economia Popular Solidária do Espírito Santo FETAES - Federação dos Trabalhadores na Agricultura no Estado do Espírito Santo 
FINEP - Financiadora de Estudos e Projetos

FMI - Fundo Monetário Internacional

FSM - Fórum Social Mundial

GTB - Grupo de Trabalho Brasileiro

IBASE - Instituto Brasileiro de Análises Sociais e Socioeconômicas

IBGE - Instituto Brasileiro de Geografia e Estatística

IPEA - Instituto de Pesquisa Econômica Aplicada

ITCP - Incubadora Tecnológica de Cooperativas Populares

MDA - Ministério do Desenvolvimento Agrário

MST - Movimento dos Trabalhadores Sem Terra

TEM - Ministério do Trabalho e Emprego

MSTR - Movimento Sindical dos Trabalhadores e Trabalhadoras Rurais

OCB - Organização das Cooperativas do Brasil

OCDE - Organização para Cooperação e Desenvolvimento Econômico

OCEs - Organização das Cooperativas Estaduais

OIT - Organização Internacional do Trabalho

ONG - Organização Não Governamental

PACS - Instituto de Políticas Alternativas para o Cone Sul

PEA - População Economicamente Ativa

PEFES - Política Estadual de Fomento à Economia Solidária no Estado do

Espírito

PIB - Produto Interno Bruto

PLANSEQ - Plano Setorial de Qualificação

PLS - Projeto de Lei do Senado $n^{\circ} 171$

$P N Q$ - Plano Nacional de Qualificação

PNUD - Programa das Nações Unidas para o Desenvolvimento

PROEMPREGO - Programa de Expansão e Melhoria da Qualidade de Vida

do Trabalhador

PROGER - Programa de Geração de Emprego e Renda

PRONAF - Programa Nacional de Fortalecimento da Agricultura Familiar

PRONINC - Programa Nacional de Incubadoras de Cooperativas Populares 
RBSES - Rede Brasileira de Socio-Economia Solidária

RITCP - Rede de Incubadoras Tecnológicas de Cooperativas Populares

RTS - Rede de Tecnologia Social

SCA - Sistema Cooperativista dos Assentados

SEBRAE - Serviço Brasileiro de Apoio à Micro e Pequena Empresa

SENAC - Serviço Nacional do Comércio

SENAES - Secretaria Nacional de Economia Solidária

SENAI - Serviço Nacional de Aprendizagem Industrial

SIES - Sistema de Informações em Economia Solidária

UFRJ - Universidade Federal do Rio de Janeiro

UFES - Universidade Federal do Estado do Espírito Santo

UNICAFES - União Nacional das Cooperativas da Agricultura Familiar e Economia Solidária

UNISOL - União e Solidariedade das Cooperativas Empreendimentos de Economia Social do Brasil

UNITRABALHO - Rede Interuniversitária de Estudos e Pesquisas sobre o Trabalho 


\section{Lista de tabelas}

Tabela 1 - Quantidade e percentual de unidades de Economia 146 Solidária por unidade da federação/região

Tabela 2 - Remuneração média mensal obtida nas unidades de 158 Economia Solidária no Estado do Espírito Santo 


\section{Lista de Gráficos}

Gráfico 1 - Unidades de Economia Solidária por ano de início - 147 segundo grandes regiões do Brasil

Gráfico 2 - Forma de organização no Brasil 148

Gráfico 3 - Unidades de Economia Solidária por ano de início - 149 segundo forma de organização no Brasil

Gráfico 4 - Motivos para criação das unidades produtivas de 150 Economia Solidária no Brasil

Gráfico 5 - Formas de organização no estado do Espírito Santo 155

Gráfico 6 - Quantidade de unidades produtivas por ano de início / 156 Espírito Santo

Gráfico 7 - Motivos de criação unidades por ano de início/Espírito 157 Santo

Gráfico 8 - Atividades realizadas de forma coletiva/ Espírito Santo 159

Gráfico 9 - Entidades que apoiaram as unidades produtivas de 160 Economia Solidária / Espírito Santo 
"O trabalho, como criador de valores-de-uso, como trabalho útil, é indispensável a existência do homem - quaisquer que sejam as formas de sociedade -, é necessidade natural e eterna de efetivar o intercâmbio material entre o homem e a natureza e, portanto, de manter a vida humana".

Karl Marx. 